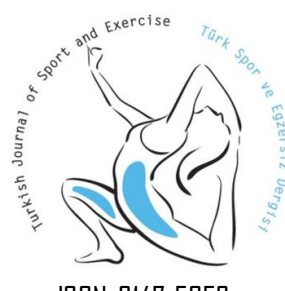

ISSN: 2147-5652

\title{
Anterior intermeniscal ligament: an anatomic study of its insertion pattern in Ghanaians
}

\author{
Ato Ampomah BROWN \\ Department of Anatomy, School of Medical Sciences, University of Cape Coast. \\ Address correspondence to Ato Ampomah Brown, ampomahbrown@yahoo.com.
}

\begin{abstract}
The purpose of this study was to identify the various patterns of attachment of the anterior intermeniscal ligament that is predominate in the Ghanaian as there is no known publication on this subject. The study was conducted in the Department of Anatomy of the School of Medical Sciences, University of Cape Coast and involved 42 paired cadaveric knees, from 16 males and 5 females. The incidence of the AIML was $40.5 \%$. The mean length of the AIML was $28.95 \mathrm{~mm}$; the mean width was $1.94 \mathrm{~mm}$, while the mean distance from mid-portion of the AIML to the insertion of the anterior cruciate ligament was $4.32 \mathrm{~mm}$. Type I pattern of attachment was the most common pattern of insertion observed (64.7\%), followed by type II (29.4\%) and then type III (5.9\%). The incidence of the AIML may be lower in the Ghanaian populace than most reported studies.
\end{abstract}

Keywords: Anterior intermeniscal ligament, knee, meniscus.

\section{INTRODUCTION}

The anterior intermeniscal ligament (AIML) of the knee, which is also referred to as the transverse geniculate ligament, menisco-meniscal ligament and the intermeniscal ligament is one of the intracapsular ligaments in the knee joint. Gray's anatomy describes it as connecting the convex margin of the lateral meniscus to the anterior horn of the medial meniscus. There is much disparity among researchers on its occurrence in the knee joint. Studies have recorded incidence ranging from $53 \%$ to $94 \%(1,3,4,6,8,10)$, Gray's anatomy however describes it as being often absent.

Its exact function in the knee is till an issue of debate amongst researchers. It has been suggested that it may augment the attachment of the anterior horns of the menisci of the knee $(5,6,7)$ and that is may also play a role in propioception $(1,9)$. The aim of this study is to find out the incidence of the AIML in the Ghanaian subjects as there is scanty data on it.

\section{MATERIAL \& METHOD}

The study was conducted in the Department of Anatomy of the School of Medical Sciences, University of Cape Coast using 42 paired cadaveric knees, from 16 males and 5 females. The knee joint was opened by first removing the skin around the knee and transecting the quadriceps femoris muscle proximal to the patella and reflecting the patella inferiorly. The medial and lateral collateral ligaments were then released and the knee gently flexed.

The AIML was sought for by carefully dissecting the infra patellar fat pad. When present, its length, width, as well as the distance from its mid-portion to the insertion of the anterior cruciate ligament (ACL) was recorded.

The different attachment patterns of the AIML was noted and classified using the classification system described by Nelson and LaPrade (6). They identified three different attachment patterns of the AIML; types I to III.

Type I-- the ligament attaches directly to the anterior horn of the medial meniscus and the anterior margin of the lateral meniscus (classically described attachment in most literature).

Type II--the ligament attaches medially to the most-anterior margin of the medial meniscus and attaches laterally to the joint capsule anterior to the lateral meniscus.

Type III-this attachment pattern consists of two types, the main attachment points of the AIML, both 
medially and laterally is the anterior capsule. The first had attachments to the anterior capsule only, with no meniscal insertions and the second had an additional fine fascial attachment on both anterior meniscal margins.

\section{RESULTS}

The AIML was present in 17 (40.5\%) knees. The mean length of the AIML was $29.0 \mathrm{~mm}$ and ranged from $39.2-10.5 \mathrm{~mm}$, the mean width was $1.9 \mathrm{~mm}$ and ranged from $0.7-2.5 \mathrm{~mm}$, while the mean distance from mid-portion of the AIML to the insertion of the anterior cruciate ligament was $4.3 \mathrm{~mm}$ and ranged from $0.6-10.2 \mathrm{~mm}$. Five $(29.4 \%)$ cadavers had unilateral AIML, of the 5 cadavers 3 had the AIML present in the left knee with 2 cadaver having it present in the right knee. Type I pattern of attachment was identified in 11 $(64.7 \%)$ knees, type II pattern of attachment in 5 $(29.4 \%)$ knees, with type III in 1 (5.9\%) knee. The type III was of the variant with only an anterior capsule attachment and no meniscal insertion.

The ligament was single stranded in 15 knees and bifid in 2 knees (one in the left and the other in the right of two different cadavers).

With the exception of one specimen, all cadavers that had the AIML occurring bilaterally had identical pattern of attachment bilaterally. There were 2 knees in which the anterior horn of the medial meniscus was anchored solely by the AIML.

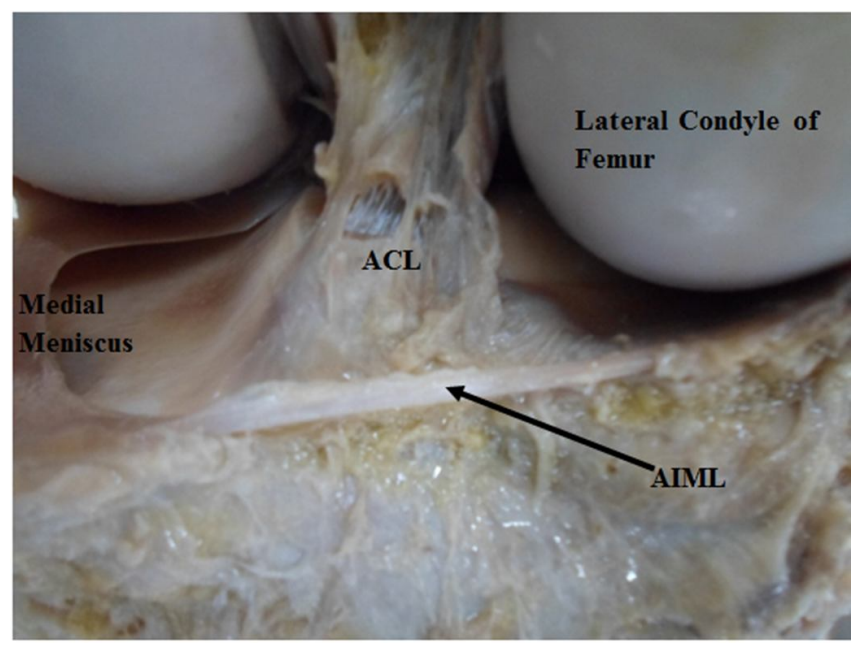

Figure 1. Single stranded AIML showing type 1 attachment pattern.

\section{DISCUSSION}

In this study the AIML was present in $40.5 \%$ of specimen; most studies on the AIML have reported an incidence higher than $50 \%(1,3,4,6,8,10)$. Suggesting that, the incidence of the AIML may be lower in the Ghanaians populace, an observation that has previously been made by Brown (2).

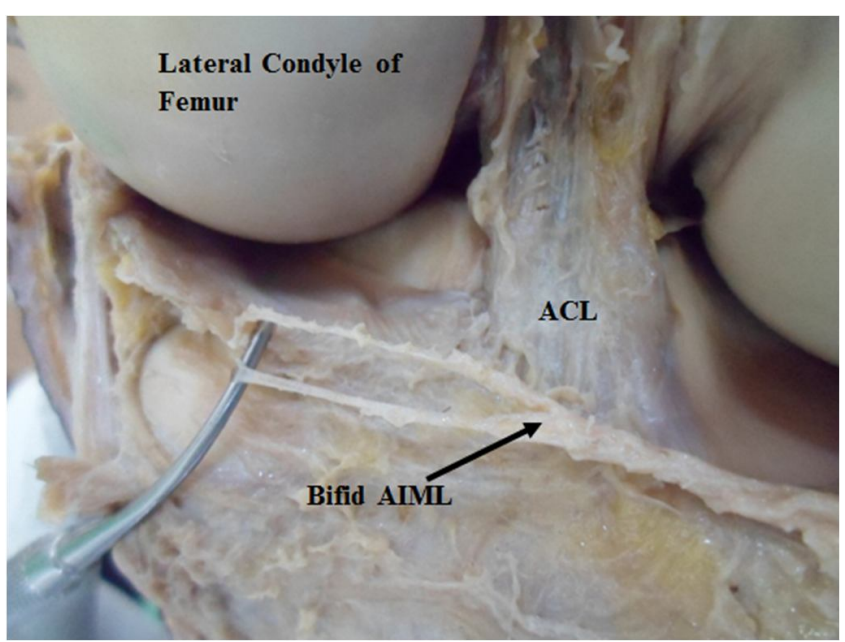

Figure 2. AIML with double stranding from mid-course to lateral insertion.

The AIML was identified in most knees as a single strand. There were however 2 knees that had bifid (double stranded) ligaments. The doubling of the AIML has been described by other researchers $(1,8)$.

Three studies have all reported the mean length of the AIML to be greater than $30.0 \mathrm{~mm}$. $(4,6,8)$ The mean length of the AIML in this study was $29.0 \mathrm{~mm}$. The width of the AIML was $1.9 \mathrm{~mm}$, which fall within the range of mean width of $1.8-3.3 \mathrm{~mm}$ reported in previous studies $(4,6,8)$. The average distance from the ACL was $4.3 \mathrm{~mm}$. Nelson and LaPrade (6) recorded a distance of $7.8 \mathrm{~mm}$, Marcheix et al. (4), $12 \mathrm{~mm}$ whilst Tubbs et al. (8) measured a distance of $2.5 \mathrm{~mm}$. It has been suggested that this close proximity of the AIML to the ACL makes it susceptible to injury during surgeries that involve the ACL (6)

The most common attachment pattern for the AIML in this study was type I (64.7\%) a finding similar to other studies $(4,6)$ with the majority of the knees exhibited the classical pattern of insertion (type I), contrary to the findings of Nelson and LaPrade (6) who reported that though type I pattern of attachment was the most common in their study it accounted for less than half of the specimen leaving the majority of the knees with alternate attachment patterns.

The AIML was present bilaterally in $70.6 \%$ of specimen in contrast to the findings of Tubbs et al. (8) who found only $36 \%$ of specimen to have the ligament present in both knees. Only one specimen exhibited 
different patterns of attachment of the AIML bilaterally. The said cadaver had type III attachment pattern in the right knee and type I in the left knee.

In our study 2 knees had only the AIML anchoring the anterior horn of the medial meniscus. This type of insertion of the anterior horn of the medial meniscus has been previously reported in other studies $(1,2,6)$. Even though the function of the AIML is still being debated, the speculation among these researchers is that the AIML may have significant biomechanical implication in the function of this particular knee variant in which the AIML appears to be the sole anchor of the anterior horn of the medial meniscus. Care must therefore be taken to preserve the AIML during procedures that are likely to damage it.

In conclusion; the incidence of the AIML appears to be lower in the Ghanaian population. Though the function of the AIML is still controversial it is the opinion of this author that its integrity should be preserved during knee surgeries, (especially surgeries that involve the ACL where the AIML is likely to be damaged) as the AIML may have some biomechanical function is some specific knee variants.

\section{REFERENCES}

1. Berlet GC, Fowler PJ. The anterior horn of the medial meniscus: An anatomic study of its insertion. Am J Sports Med, 1998; 26: 540-543.

2. Brown AA. The insertion of the anterior horn of the medial meniscus: an anatomic study. Muscles, Ligaments and Tendons Journal, 2013; 3(3): 210-212.

3. Kohn D, Moreno B. Meniscus insertion anatomy as a basis for meniscus replacement: a morphological cadaveric study. Arthroscopy, 1995; 11: 96-103.

4. Marcheix PS, Marcheix B, Siegler J, Bouillet P, Chaynes P, Valleix D, Mabit C. The anterior intermeniscal ligament of the knee: an anatomic and MR study. Surgical and radiologic anatomy, 2009; 31(5): 331-334.

5. Muhle C, Thompson WO, Sciulli R, Pedowitz R, Ahn JM, Yeh L, Clopton P, Haghighi P, Trudell DJ, Resnick D. Transverse ligament and its effect on meniscal motion: Correlation of kinematic MR imaging and anatomic sections. Invest Radiol, 1999; 34: 558-565.

6. Nelson EW, LaPrade RF. The anterior intermeniscal ligament of the knee an anatomic study. The American Journal of Sports medicine, 2000; 28(1), 74-76.

7. Stranding S. Gray's anatomy: Anatomical basis of clinical practice. 39th $\mathrm{ed}$. Elsevier Churchill Livingstone. 2005, pp 1477.

8. Tubbs RS, Mechelson J, Loukas M, Shoja MM, Ardalan MR, Salter EG, Oakes WJ. The transverse genicular ligament: anatomical study and review of the literature. Surg Radiol Anat, 2008; 30(1): 5-9.

Turk ل Sport Exe 2014; I6(I): I-3

๑ 2014 Department of Physical Education and Sport, Selcuk University
9. Yildirim F B, Soyuncu Y, Oguz N, Aydin AT, Sindel M, Ustunel I. Anterior intermeniscal ligament: An ultrastructural study. Ann Anat, 2007; 189; 510-514.

10. Zivanovic S. Menisco-meniscal ligaments of the human knee joint. Anat Anz, 1974; 135: 35-42. 